\title{
In situ detection of antigen-specific $T$ cells in cryo-sections using MHC class I tetramers after dendritic cell vaccination of melanoma patients
}

\author{
I. J. M. De Vries • M. R. Bernsen • W. L. van Geloof • N. M. Scharenborg • \\ W. J. Lesterhuis · P. D. M. Rombout - G. N. P. Van Muijen · C. G. Figdor • \\ C. J. A. Punt · D. J. Ruiter · G. J. Adema
}

Received: 15 November 2006 / Accepted: 21 February 2007 / Published online: 18 April 2007

(C) Springer-Verlag 2007

\begin{abstract}
Application of tetrameric MHC class I-peptide complexes has significantly improved the monitoring of antigen-specific $\mathrm{T}$ cell immune responses in mouse models as well as in clinical studies. Especially MHC class I tetramer analysis of tumor-specific $\mathrm{T}$ cells in suspension or on thick vibratome sections from viable tissue has been proven extremely useful. Using the well-characterized mouse tyrosinase-related-protein- 2 specific cytotoxic T cell (CTL) clone LP9, we now developed a method that allows for
\end{abstract}

De Vries and Bernsen contributed equally to this study.

N. M. Scharenborg · C. G. Figdor · G. J. Adema

Department of Tumor Immunology,

Radboud University Nijmegen Medical Centre,

Nijmegen Centre for Molecular Life Sciences,

Nijmegen, The Netherlands

G. J. Adema ( $\square)$

Department of Tumor Immunology, NCMLS/278 TIL,

University Medical Centre, Postbox 9101,

6500 HB Nijmegen, The Netherlands

e-mail: g.adema@ncmls.ru.nl

M. R. Bernsen · W. L. van Geloof · P. D. M. Rombout ·

G. N. P. Van Muijen · D. J. Ruiter

Department of Pathology, Radboud University Nijmegen Medical

Centre, Nijmegen Centre for Molecular Life Sciences,

Nijmegen, The Netherlands

I. J. M. De Vries

Department of Tumor Immunology, Medical Oncology and Pediatric Hemato-Oncology, Radboud University Nijmegen

Medical Centre, Nijmegen Centre for Molecular Life Sciences,

Nijmegen, The Netherlands

W. J. Lesterhuis · C. J. A. Punt

Department of Medical Oncology, Radboud University Nijmegen

Medical Centre, Nijmegen Centre for Molecular Life Sciences,

Nijmegen, The Netherlands specific identification of T cells with MHC class I tetramers in $8 \mu \mathrm{m}$ thick, chemically fixed cryosections. The protocol was validated in a murine influenza virus-infection model. Moreover, analysis of delayed type hypersensitivity (DTH) skin biopsies from melanoma patients vaccinated with peptide-loaded mature dendritic cells, revealed the presence and location of anti-tumor CTLs. The specificity of the CTLs detected in situ correlated with both the DTH challenge specificity and reactivity of cell suspensions derived from the same biopsies. Collectively, our data demonstrate that in situ MHC class I tetramer staining provides a valuable tool to reveal the presence and anatomical location of specific CTLs in frozen tissue following immunebased treatment strategies in cancer patients.

\section{Introduction}

Immune-based treatment strategies are considered a valuable treatment option for cancer patients. Objective responses have been obtained with a variety of immunotherapy approaches especially in melanoma patients [18, 20]. Recently dendritic cell (DC)-based vaccination studies have received increasing attention and yielded promising results in cancer patients [5, 13, 16, 17, 19, 32]. Development and validation of immunologically based treatment strategies is, however, critically dependent on appropriate monitoring of both the immunological response and the clinical response to define the correlates of treatment efficacy $[6,25]$. The availability of soluble multimeric MHC-peptide complexes has broadened the options for immune monitoring since specific CTLs can be identified and isolated directly $[1,22,34]$. In most studies MHC class I tetramers were only effective for analysis of T cells that are in suspension [24, 26]. However, like for functional $\mathrm{T}$ cell assays, e.g., ELI-spot assay 
and cytotoxicity assay, this does not yield any information regarding the localization of specific $\mathrm{T}$ cells within tissues $[7,8,15,23]$. Therefore, in situ detection of specific T cells in tissues would be highly informative in revealing the location and unraveling possible mechanisms of the anti-tumor response in vivo. In this paper we report on the development of a protocol that allows for in situ detection of antigen specific T-cells in frozen and fixed tissue sections. The protocol was first developed using mouse $\mathrm{H}-2 \mathrm{~K}^{\mathrm{b}}-\mathrm{TRP} 2_{180}$ tetramers and a mouse tissue model containing TRP2-specific CTLs [28]. Validation of the protocol was performed in a murine viral infection model and in delayed type hypersensitivity (DTH) biopsies from melanoma patients treated with tumor peptide-loaded DCs [9].

\section{Materials and methods}

\section{MHC class I tetramers}

Tetrameric, MHC class I-peptide complexes with specificities for mouse $\mathrm{H}-2 \mathrm{~K}^{\mathrm{b}}-\mathrm{TRP} 2_{180-187}, \mathrm{H}-2 \mathrm{~K}^{\mathrm{b}}-\mathrm{OVA}_{257-264}$, $\mathrm{H}-2 \mathrm{D}^{\mathrm{b}}$-influenza A virus $\mathrm{NP}_{366-374}$, and human HLA-A2.1gp100 ${ }_{154-162}$; HLA-A2.1-gp100 $280-288$ and HLA-A2.1-tyrosinase $_{369-377}$ were kindly provided by Drs T. Schumacher and H. Spits from the Netherlands Cancer Institute (Amsterdam, The Netherlands) or purchased from Immunomics, Beckman Coulter (Inc, San Diego, USA). Other MHC class I tetramers; HLA-A2.1-MART- $1_{26-35}$, HLA-A2.1-HIV$\operatorname{gag}_{77-85}$ and HLA-A2.1-EBV $280-288$ were purchased from Immunomics. Each MHC class I tetramer was validated by staining of a CTL line specific for HLA-A2.1 in association with the peptide of interest.

\section{Antibodies}

Primary antibodies used for the detection of $\mathrm{CD} 8^{+}$cells were WT82 [21] and HIT8a (BD Pharmingen). Secondary antibodies used: biotinylated rabbit anti-streptavidin (code 200-4695), rabbit anti-phycoerythrin (code 200-4199), rabbit anti-streptavidin (code 200-4195) purchased from Rockland Gilbertville, Pa, mouse anti-streptavidin (clone DD9; Upstate Biotechnology) and goat anti-streptavidin (Biogenesis, Poole, UK), goat-anti-rabbit-Alexa594, goatanti-mouse-Alexa498 (Molecular Probes, Europe BV, Leiden, The Netherlands).

\section{Tissues}

For development and optimization of a protocol suitable for in situ detection of CTLs we used the $\mathrm{H}-2 \mathrm{~K}^{\mathrm{b}}$-restricted TRP2-specific clone LP9 [28]. LP9 cells were injected in the hind leg muscles of C57B16 mice. After 5 min the mice were sacrificed and the injected muscles were dissected, snap frozen in liquid nitrogen and stored at $-80^{\circ} \mathrm{C}$ until further use.

For validation of the optimized protocol developed with the LP9-containing muscle tissue, staining with MHC class I tetramers was also performed on spleens from virusinfected and non-infected B6.Ly5.1 mice and on biopsies from DTH lesions from melanoma patients.

The spleens from B6.Ly5.1 mice were kindly provided by Drs F. Vyth-Dreese and T. Schumacher from the Netherlands Cancer Institute (Amsterdam, The Netherlands). In this virus infection model B6.Ly5.1 mice had received an adoptive transfer of B10F5 lymph node cells. B10F5 mice are transgenic for the $\mathrm{H}-2 \mathrm{D}^{\mathrm{b}}$-restricted, influenza $\mathrm{A}$ virus $\mathrm{NP}_{366}$-specific, TCR [14]. Three days after adoptive transfer, part of the mice were infected with influenza A virus. Ten days after adoptive transfer spleens were isolated from infected and non-infected mice.

\section{In situ staining with MHC class I tetramer}

From snap frozen material (muscles or biopsies) $8 \mu \mathrm{m}$ thick cryosections were cut and air-dried and used immediately or stored at $-80^{\circ} \mathrm{C}$ until use. Tissue sections were fixed with $4 \%$ paraformaldehyde (PFA) for $3 \mathrm{~min}$. Non-specific protein binding was prevented by using $20 \%$ normal goat serum in PBS for 20 min. Incubation with MHC class I tetramer was performed overnight at $4{ }^{\circ} \mathrm{C}$ at an approximate MHC class I tetramer concentration of $5 \mu \mathrm{M}$ in $4 \%$ normal goat serum and PBS. After washing with PBS specific MHC class I tetramer binding was fixed with 4\% PFA for $20 \mathrm{~min}$. Sections were incubated with or without anti-CD8 at a concentration of $2 \mu \mathrm{g} / \mathrm{ml}$ and after washing they were incubated with polyclonal rabbit serum against streptavidine (1/800 diluted, Rockland). Binding of MHC class I tetramer was visualized using a polyclonal goat-anti-rabbitAlexa594 at a 1/500 dilution, resulting in a red fluorescent signal. CD8 was visualized using a polyclonal goat-antimouse-Alexa498 (1/500 dilution; $30 \mathrm{~min}$ at room temperature), resulting in a green fluorescent signal.

Sections were counterstained with DAPI resulting in a blue fluorescent staining of the nucleus. Washing in PBS was performed between each incubation. Finally, sections were then mounted with fluorescent mounting medium containing anti-fade.

FITC and TRITC signals were collected on a Leica Leitz DMRBE. Images were taken using a $\times 10, \times 40$ or $\times 63$ objective. Color photomicrographs were generated from electronic overlays.

\section{Patients}

Melanoma patients (stage III and IV according to AJCC criteria [4]) participating in ongoing protocols, in which the 

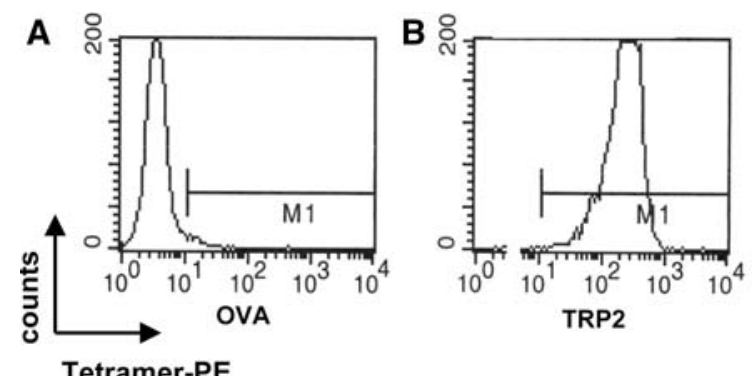

Tetramer-PE
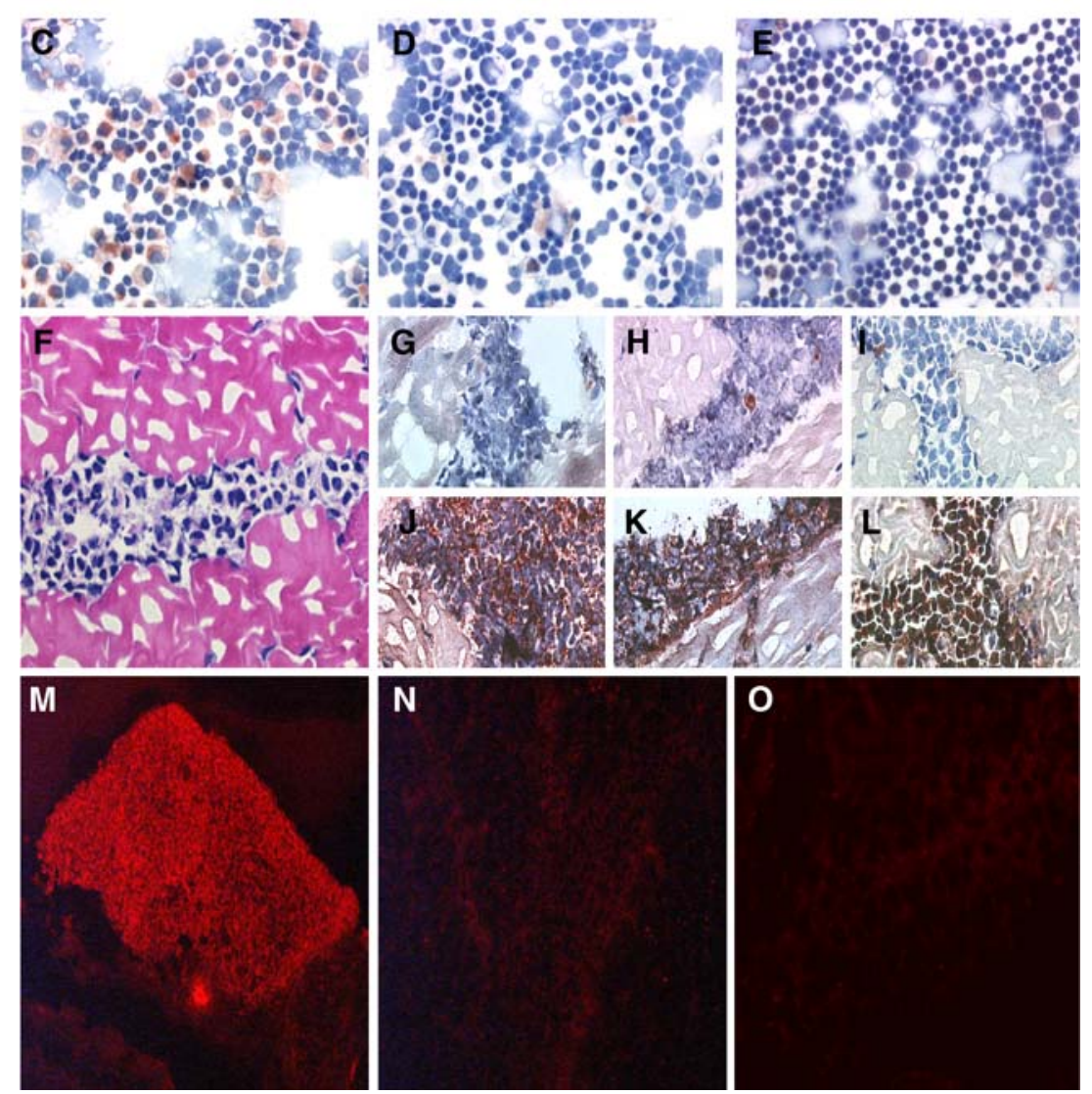

Fig. 1 In situ detection of antigen-specific T cells. Flow cytometric analysis of tetramer binding by LP9 T cells, control tetramer $\mathrm{H}-2 \mathrm{~K}^{\mathrm{b}}$ OVA (a) and relevant tetramer $\mathrm{H}-2 \mathrm{~K}^{\mathrm{b}}-\mathrm{TRP} 2_{180}$ (b). Positive staining of a cytological preparation containing LP9 cells and normal C57BL splenocytes was only observed with $\mathrm{H}-2 \mathrm{~K}^{\mathrm{b}}-\mathrm{TRP} 2_{180}$ tetramer (c) and not without tetramer (negative control) (d). Staining of normal splenocytes with $\mathrm{H}-2 \mathrm{~K}^{\mathrm{b}}-\mathrm{TRP} 2_{180}$ tetramer did not result in a positive signal (e). H\&E-stained section of LP9-containing muscle tissue (f). Improved morphology and signal to noise ratios of in situ detection of antigen specific $\mathrm{T}$ cells in LP9-containing muscle tissue sections stained histochemically with specific tetramers $(\mathbf{j}-\mathbf{l})$ or negative

immune responses of DC vaccines are studied were included [10]. Eligibility criteria included HLA-A2.1 phenotype, melanoma expressing gp100 and tyrosinase, and WHO performance status 0 or 1 . Additional eligibility criteria are described previously. The studies were approved by the local regulatory committee, and written informed consent was obtained from all patients. control solution (without tetramer) (g-i) using the ABC-peroxidase kit with AEC (red-brown staining) as substrate. $\mathbf{g}$, $\mathbf{j}$ Without blocking with normal goat serum and PFA-fixation prior to staining. $\mathbf{h}, \mathbf{k}$ With normal goat serum blocking but without PFA-fixation prior to staining. i, I With blocking with normal goat serum and PFA-fixation prior to staining. LP9-containing muscle tissue sections stained with or without tetramers with fluorescent microscopy visualization. Positive staining was observed after incubation with specific $\mathrm{H}-2 \mathrm{~K}^{\mathrm{b}}-\mathrm{TRP} 2_{180}$ tetramers (m) and not without the addition of tetramer (n) or after incubation with control tetramer $\mathrm{H}-2 \mathrm{~K}^{\mathrm{b}}-\mathrm{OVA}$

\section{Delayed type hypersensitivity}

One to 2 weeks after DC vaccination, a DTH skin test was performed. Briefly, unpulsed DC, DC pulsed with the indicated peptides, DC pulsed with KLH, and DC pulsed with the indicated peptides plus KLH $\left(2-10 \times 10^{5} \mathrm{DC}\right.$ each) were injected i.d. [9]. 
From positive DTH sites $(>2 \mathrm{~mm})$, punch biopsies $(6 \mathrm{~mm})$ were obtained and cut in half; one part was embedded in Tissue-tek, snap frozen in liquid nitrogen and stored at $-80^{\circ} \mathrm{C}$ until further use. The other part was cut in pieces and cultured in RPMI/7\%HS supplemented with IL-2 $(100 \mathrm{U} / \mathrm{ml})$. Every 7 days, half of the medium was replaced by fresh IL-2-containing RPMI/7\%HS. After 2-4 weeks of culturing, $T$ cells were tested for specificity.

MHC class I tetramer staining of cells in suspension

DTH-derived cells $\left(1 \times 10^{5}\right.$ cells in $\left.10 \mu \mathrm{l}\right)$ or PBMC $\left(1 \times 10^{6}\right.$ cells in $\left.10 \mu \mathrm{l}\right)$ were incubated with PE-labeled MHC class I tetramers and FITC-conjugated mAbs either directed against CD4 or CD8 (both Becton Dickinson) for $1 \mathrm{~h}$ at RT. After washing, the samples were analyzed by flow cytometry.

\section{Cytotoxicity assay}

Cytotoxic activity of DTH-infiltrated lymphocytes was measured using the chromium release assay as described previously [3]. Briefly, T2 or BLM cells (a melanoma cell line expressing HLA-A2.1 and no endogenous expression of gp100 and tyrosinase), transfected with control antigen G250, or with the antigens of interest (gp100 and tyrosinase) were incubated with $100 \mu \mathrm{Ci} \mathrm{Na}{ }_{2}\left[{ }^{51} \mathrm{Cr}\right] \mathrm{O}_{4}$ (Amersham,
Bucks, UK) and, after washing, added to lymphocytes $\left(10^{5}\right.$ cells) and unlabeled $\mathrm{K} 562$ cells $\left(10^{4}\right.$ cells $)$ in triplicate wells of a round bottom microtiter plate (E/T ratio 10/1). After $4 \mathrm{~h}$, supernatants were harvested and radioactivity was measured. The specific percentage of cytotoxicity was defined by: [(experimental release - spontaneous release $) \div$ (maximum release - spontaneous release) $] \times 100 \%$.

\section{Results and discussion}

In situ detection of antigen specific T cells with MHC class I tetramers: protocol requirements

To develop a protocol that allows in situ detection of CTLs with MHC class I tetramers on cryo-sections, we used the well-characterized $\mathrm{H}-2 \mathrm{~Kb}$-restricted $\mathrm{TRP} 2_{180^{-}}$ specific CTL clone LP9 and the corresponding $\mathrm{H}-2 \mathrm{~K}^{\mathrm{b}}$ TRP2 tetramers [28]. As shown in Fig. 1 A-B, LP9 CTLs in suspension were readily stained by TRP2-specific tetramers but not by OVA-specific tetramers recognizing the OVA $_{\text {SIINFEKL }}$ peptide presented by the same $\mathrm{H}-2 \mathrm{~K}^{\mathrm{b}}$ molecule. For immunocytochemical stainings, cytospins were generated of LP9 cells, either alone or mixed with C57B16 thymocytes. Artificial tissues containing LP9 CTLs were obtained by injection of these CTLs in femoral muscles of C57B16 mice, and freezing of the dissected injection site. To detect CTLs, cytospins (Fig. 1c-e) and artificial
Fig. 2 In situ detection of a virus-specific response. Tissue sections from spleens derived from mice that received adoptive transfer with $\mathrm{H}-2 \mathrm{D}^{\mathrm{b}}-\mathrm{NP}_{366}$ transgenic lymph node cells stained with tetramer (red) or negative control solution (without tetramer), CD8 (green) and DAPI (blue nuclear staining). a Spleen from a noninfected mouse stained with specific tetramer showing an occasional very bright tetramer positive cell ( $r e d)$. b Spleen from a virus-infected mouse stained with specific tetramer showing clusters of positive cells (not seen in non-infected mice or in negative control stainings). c Spleen from a virusinfected mouse stained with negative control solution. d CD8 Staining of spleen from an infected mouse
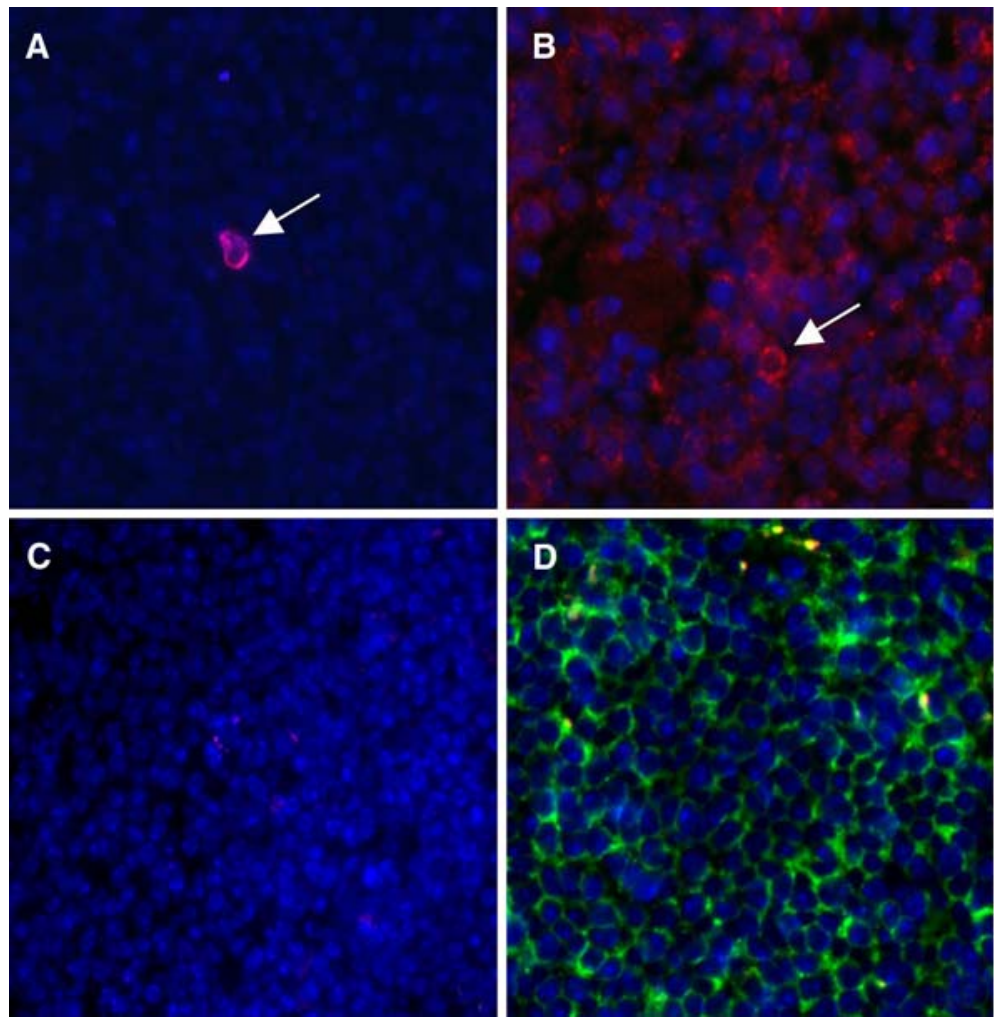
Table 1 Overview of tetramerpositive cells found in DTH biopsies from melanoma patients vaccinated with DC loaded with tyrosinase and gp100 peptide

\begin{tabular}{|c|c|c|c|c|c|c|c|}
\hline & \multirow[t]{2}{*}{ DTH challenge } & \multicolumn{6}{|l|}{ Tetramers } \\
\hline & & Tyrosinase & gp100 154 & $\mathrm{gp} 100_{280}$ & MART-1 & HIVgag & EBV \\
\hline Patient 1 & $\mathrm{DC}+\mathrm{gp} 100_{280}$ & - & - & + & - & - & ND \\
\hline \multirow[t]{2}{*}{ Patient 2} & $\mathrm{DC}+\mathrm{gp} 100_{280}$ & - & - & + & - & - & ND \\
\hline & $\mathrm{DC}+3$ peptides & - & - & - & - & - & ND \\
\hline \multirow[t]{4}{*}{ Patient 3} & $\mathrm{DC}+3$ peptides & + & - & + & - & - & - \\
\hline & $\mathrm{DC}+3$ peptides $+\mathrm{KLH}$ & - & + & + & - & ND & - \\
\hline & DC alone & - & - & - & - & ND & - \\
\hline & $\mathrm{DC}+\mathrm{KLH}$ & - & - & - & - & ND & - \\
\hline \multirow[t]{2}{*}{ Patient 4} & $\mathrm{DC}+3$ peptides & - & + & - & - & ND & - \\
\hline & $\mathrm{DC}+3$ peptides $+\mathrm{KLH}$ & - & + & - & - & ND & - \\
\hline \multirow[t]{2}{*}{ Patient 5} & $\mathrm{DC}+3$ peptides & + & + & - & - & ND & - \\
\hline & $\mathrm{DC}+3$ peptides $+\mathrm{KLH}$ & + & + & + & - & ND & - \\
\hline
\end{tabular}

tissues (Fig. 1f-i) were stained with TRP2- or control OVA-tetramers. To optimize MHC class I tetramer staining, a variety of conditions was tested, i.e., tetramer incubation time and temperature, thickness of tissue section, blocking steps to prevent unspecific binding, chemical fixation and signal enhancement. For the optimization procedure, positive MHC class I tetramer staining was compared with stainings in which MHC class I tetramers were omitted.

The results demonstrated that the thickness of the tissue sections is of importance for the signal intensity and morphology of the tissue. For tetramer detection of LP9 cells, tissue cryosections of $8 \mu \mathrm{m}$ thick were found to yield a good specific signal with adequate morphology (Fig. 1g-1). Thinner $(5 \mu \mathrm{m})$ or thicker $(10 \mu \mathrm{m})$ sections resulted in a weak specific signal and good morphology $(5 \mu \mathrm{m})$ or a good specific signal and poorer morphology $(10 \mu \mathrm{m})$ (not shown). An incubation time of $45 \mathrm{~min}$ at room temperature with MHC class I tetramers appeared to be superior to overnight incubation at $4{ }^{\circ} \mathrm{C}$ for tissue sections when no chemical fixation of the tissue was performed. However, when a mild chemical fixation (see below) was applied prior to MHC class I tetramer incubation both conditions were similarly effective.

The use of normal goat serum as a blocking step prior to MHC class I tetramer incubation resulted in an improved signal to noise ratio; however, it also resulted in poorer morphology when used on non-chemically fixed tissue sections. Fixation of the tissue with $4 \%$ PFA before (3 min) and after (20 min) incubation with MHC class I tetramers resulted in stronger specific signals and improved morphology (Fig. 1g-1). Fixation before MHC class I tetramer incubation proved to be a crucial step; fixation for considerable longer times or higher concentrations of PFA or fixation with acetone or glutaraldehyde resulted in a strong reduction or even loss of the (specific) signal. The fixation step after MHC class I tetramer incubation merely stabilized the interactions between the $\mathrm{T}$ cell receptors and MHC class I tetramers. In summary, optimal specific MHC class I tetramer staining with satisfactory morphology was achieved when $8 \mu \mathrm{m}$ thick cryosections were shortly fixed and preincubated with normal goat serum prior to MHC class I tetramer incubation and followed by fixation.

A polyclonal rabbit serum recognizing the MHC class I tetramer-associated streptavidin molecules provided signal enhancement that resulted in improved visualization of the specific CTL. On both cytospins and LP9-containing muscle tissue sections excellent results were obtained with the ABCkit as a signal amplification and visualization method (Fig. 1c-e, i, l). Unfortunately, initial tests on murine spleens and human tissue sections, revealed that this amplification and visualization method resulted in high background signals. The background observed upon amplification and visualization with the $\mathrm{ABC}$-kit in these tissues was most likely due to biotin-based, non-specific interactions. Therefore, an alternative biotin-independent, fluorochrome-based amplification and detection method was also developed that yielded excellent signal to noise ratios for those tissues in which the biotin-based protocol was sub-optimal (Fig. 1m-o). The established protocols as specified in the "Materials and methods" were used for further experiments.

In situ detection of influenza virus-specific T cells in mice

To validate the developed protocol in a more physiological setting, we applied the virus-infection model previously used to demonstrate in situ tetramer staining on 200-500 $\mu \mathrm{m}$ thick viable tissue sections [14]. In this model, lymph node cells of TCR transgenic mice specific for the $\mathrm{H}-2 \mathrm{D}^{\mathrm{b}}$ restricted influenza $A$ virus $\mathrm{NP}_{366}$ epitope were transferred to B6.Ly5.1 mice. Mice were then challenged with either influenza A virus or with vehicle. Using our protocol, $8 \mu \mathrm{m}$ 

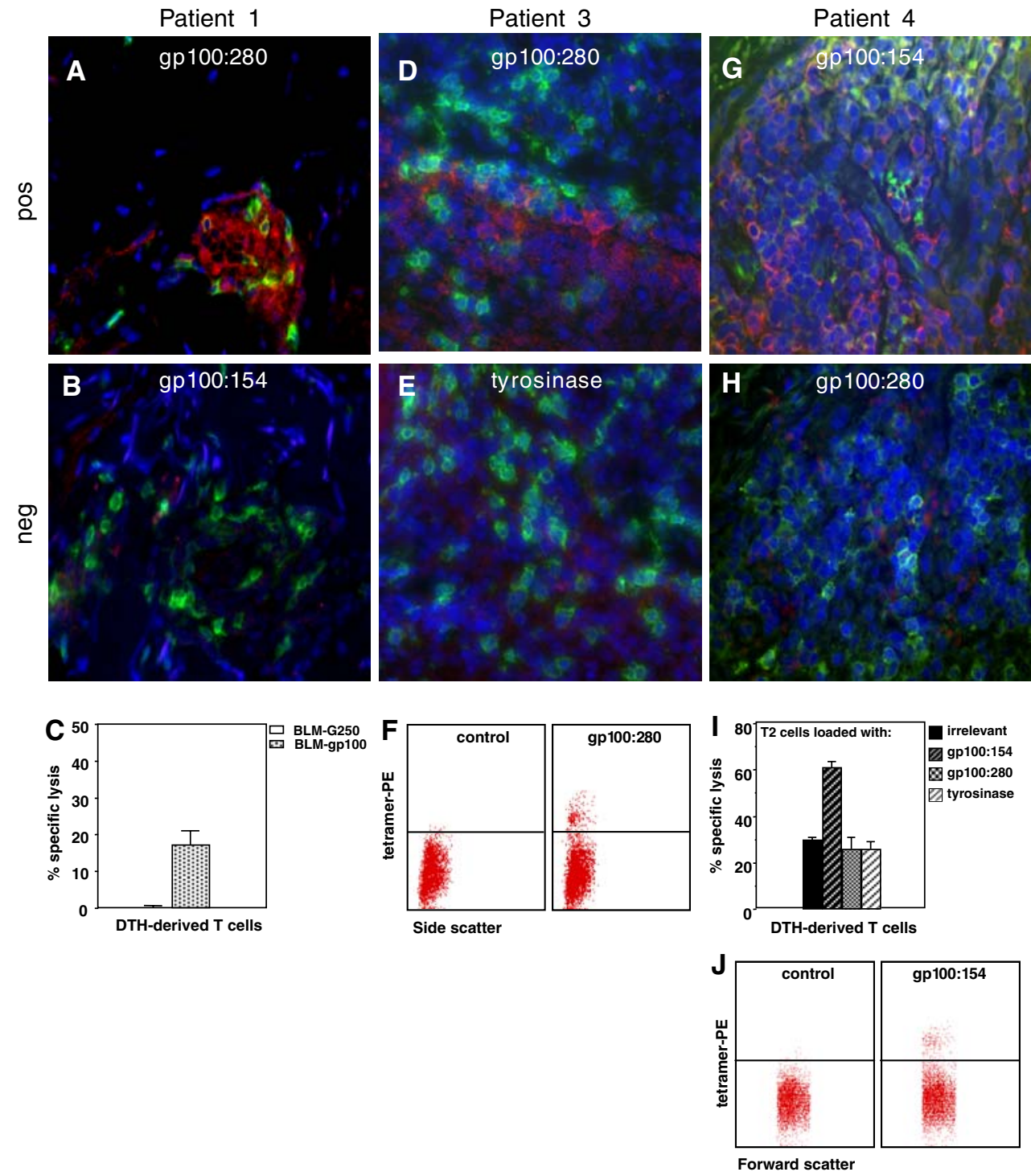

Fig. 3 Comparison of MHC class I tetramer staining in situ and MHC class I tetramer staining of cell suspensions or cytotoxic activity of cultured $\mathrm{T}$ cells of same DTH biopsies from melanoma patients vaccinated with peptide-loaded DC. Cryosections stained with MHC class I tetramers (red), anti-CD8 (green) and DAPI (blue). DTH biopsy (DC loaded with gp100:280) from patient 1. a Positive HLA-A2. 1gp $100_{280}$ tetramer staining (red). b HLA-A2.1-gp $100_{154}$ tetramer staining. c Chromium release assay showing the lysis of HLA-A2.1positive BLM cells, transfected with gp100 and not the control transfectant G250 by T cells cultured from the DTH biopsy. DTH biopsy (DC loaded with 3 peptides and KLH) from patient 3. d Positive HLAA2.1-gp $100_{280}$ tetramer staining. e Cryosection from the same area as shown in d stained with HLA-A2.1-tyrosinase tetramer. $\mathbf{f}$ Tetramer

cryosections from spleens of virus-infected or vehicleinjected B6.Ly5.1 mice were stained with influenza A virus-specific MHC class I tetramers and CD8. As shown in Fig. 2, spleens from virus-infected mice contained large clusters of MHC class I tetramer-positive cells (Fig. 2b) whereas only an occasional tetramer positive $\mathrm{T}$ cell was detected in spleens from non-infected mice (Fig. 2a). No analysis by flow cytometry of DTH-derived T cells. Depicted is the side scatter on the $x$-axis (double staining with CD8 FITC might interfere with the tetramer staining) and on the $y$-axis MHC class I tetramer PE staining. DTH biopsy (DC loaded with 3 peptides and KLH) from patient 4. g Positive HLA-A2.1-gp100 154 tetramer staining. $\mathbf{h}$ Cryosection from the same area as shown in $\mathbf{g}$ stained with HLAA2.1-gp $100_{280}$ tetramer. i Chromium release assay showing the lysis of HLA-A2.1-positive T2 cells, loaded with gp100:154 and not T2 cells loaded with irrelevant, gp100:280 or tyrosinase peptides by T cells cultured from the DTH biopsy. $\mathbf{j}$ Tetramer analysis by flow cytometry of DTH-derived T cells. Depicted is the forward scatter on the $x$-axis (double staining with CD8 FITC might interfere with the tetramer staining) and on the $y$-axis MHC class I tetramer PE staining

MHC class I tetramer positive CD8+ T cells were detected in spleens from virus-infected mice incubated with negative control solution (Fig. 2c, d). These results indicate that the developed MHC class I tetramer staining protocol specifically detected the viral specific T cells in $8 \mu \mathrm{m}$ tissue sections equally effective when compared with the $200-500 \mu \mathrm{m}$ thick viable tissue sections [14]. 

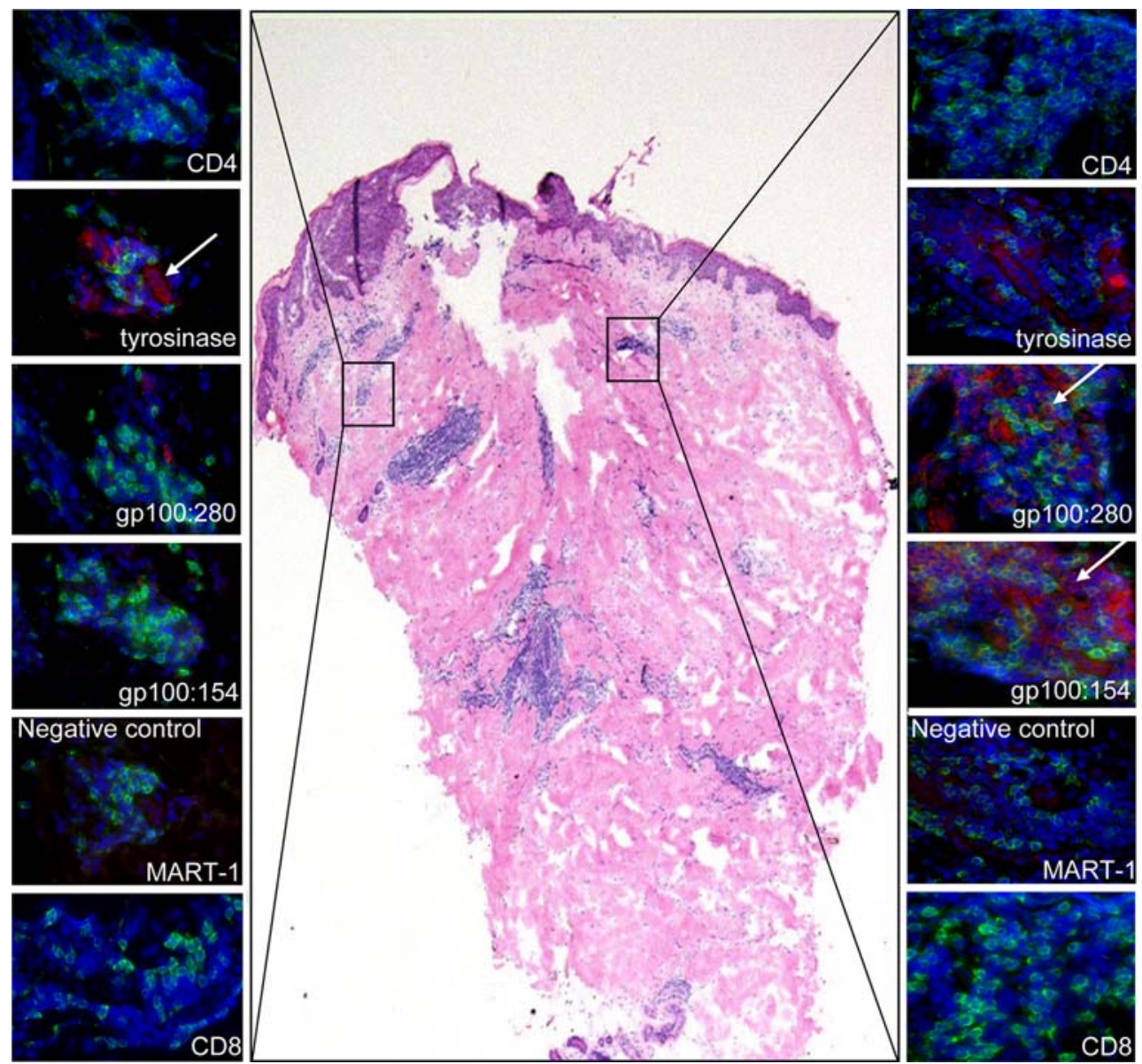

Fig. 4 Differential distribution of MHC class I tetramer-positive cells. In the middle, a low magnification of an $H \& E$ stained tissue section from patient 3 is shown. On each site of the $\mathrm{H} \& \mathrm{E}$ staining a CD4, CD8

In situ detection of vaccine-related CTL responses in melanoma patients

To determine the applicability of the in situ MHC class I tetramer staining protocol for monitoring the presence of vaccine-related CTLs in melanoma patients, we studied DTH biopsies obtained from melanoma patients participating in ongoing trials at the Radboud University Nijmegen Medical Centre. In these trials melanoma patients are treated with autologous in vitro-generated mature DC loaded with two HLA-A2.1-restricted gp100 epitopes (154-162 and 280-288), an HLA-A2.1-restricted tyrosinase-derived epitope (369-377) and KLH [9, 10]. To investigate the immune response generated in the vaccinated patients, DTH challenges were performed with mature DC and biopsies $(6 \mathrm{~mm})$ were taken from positive DTH sites.

Eight $\mu \mathrm{m}$ thick cryosections were cut from one half of these DTH biopsies and stained according to the developed protocol with a panel of relevant and non-relevant MHC class I tetramers (Table 1) and/or CD8. Initially $3 \mathrm{DTH}$ biopsies from 2 patients (patient 1 and 2) were studied. and the designated MHC class I tetramers of representative areas are shown

Both patients had received DTH with gp $100_{280}$-loaded DCs and one patient also received a DTH with DCs loaded with both gp100 peptides and the tyrosinase peptide (DC +3 peptides). In patients specific staining of clusters of cells with the HLA-A2.1-gp $100_{280}$ tetramer was observed whereas no staining with the negative control or any other MHC class I tetramer was detected (Table 1; Fig. 3a-f). In an additional 8 biopsies from 3 patients, MHC class I tetramer positive cells were found in correspondence with the DTH challenge specificity, e.g., peptide-specific T cells in DTH sites arising from a challenge with DC loaded with peptides and not in DTH sites from unloaded or KLH loaded DC (Fig. 3g-i; Table 1).

Specific T cells after short term culturing of DTH biopsies

Following a brief culture period, the specificity of $\mathrm{T}$ cells derived from half of the biopsy was analyzed by conventional methods, e.g., antigen recognition in a cytotoxicity assay or MHC class I tetramer binding. Only a minority of the DTH-derived cells were CD8 positive effector T cells. 

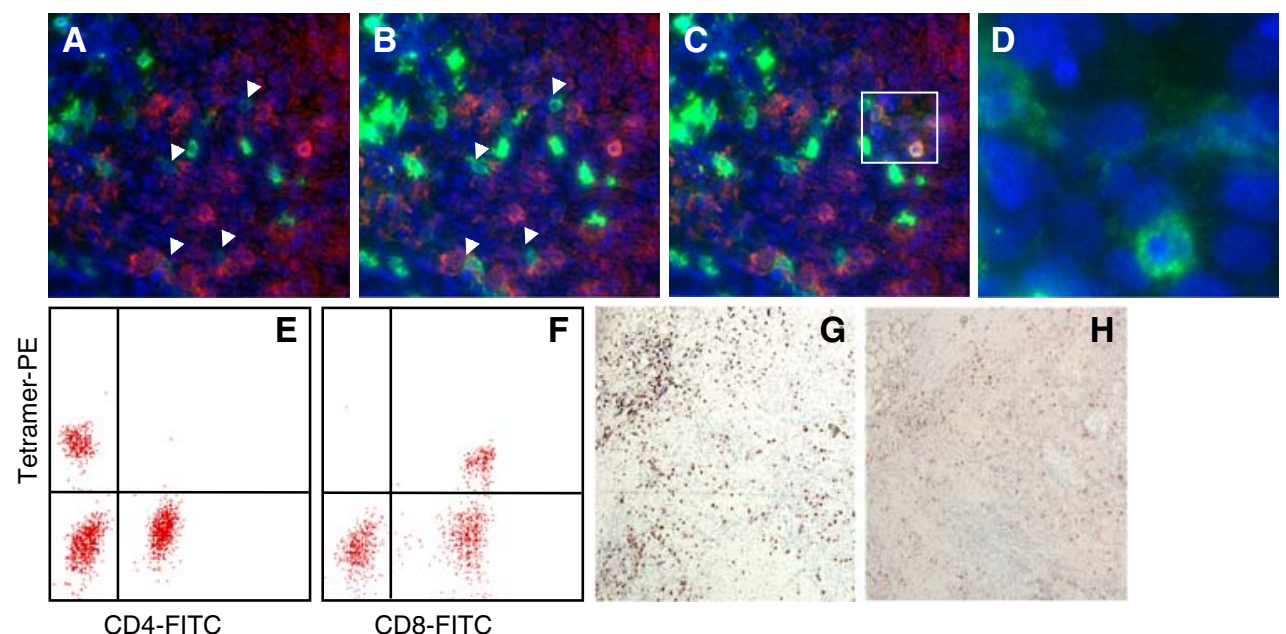

G

H

CD4-FITC

CD8-FITC

Fig. 5 CD8 staining efficiency. DTH biopsy from patient 5 (lesion DC +3 peptides) stained with HLA-A2.1-tyrosinase ${ }_{369}$ tetramer (red), anti-CD8 (green) and DAPI (blue) with increasing exposure time for the FITC filter (ranging from 2-3 s (a) to 15-20 s (c), for comparison: exposure time TRITC 7-8 s). Arrows indicate CD8+ cells that were not visible at shorter exposure times for the FITC filter. In c, only for the boxed area an increased exposure time (15-20 s) is shown to prevent overexposure from other parts of the section. d Enlarged two color overlay for green (CD8) and blue (DAPI) of the boxed area from c. Tet-

The rates of CD4+ and CD8+ $\mathrm{T}$ cells derived from DTH cultures varied between biopsies and patients $(65 \pm 21 \%$ CD4+ and $27 \pm 20 \% \mathrm{CD} 8+$ ). In 9 out of the 11 biopsies studied, identical $\mathrm{T}$ cell specificity was observed with the in situ MHC class I tetramer staining and the assays performed on the biopsy outgrowth (Fig. 3c, f, i, j). In the other two cases (patient 2: DC +3 peptides, patient 5 : $\mathrm{DC}+3$ peptides) peptide-specific $\mathrm{T}$ cells were only identified with one of the assays. As exemplified in Fig. 4, not all cell clusters within a biopsy or tissue section harbor T cells with the same specificity. Since the in situ analysis and in vitro assays were performed on different halves of the biopsies some sampling bias may occur. Also some selection of specific clones may arise from the brief culture period of the $\mathrm{T}$ cells.

\section{CD8 staining}

We noted that not all MHC class I tetramer-positive cells were clearly CD8-positive. Variation of the exposure time for the FITC filter (visualizing CD8+ cells) revealed a huge range in staining intensities for CD8+ cells (Fig. 5) as also noticed by Denkberg et al. [11]. An increased exposure time for the green filter further increased the number of CD8-positive, MHC class I tetramer-positive cells. Competitive binding between CD8 and MHC class I tetramer was also indicated by MHC class I tetramer binding tests of cells in suspension. As shown in Fig. 5, MHC class I tetramer staining intensity was reduced when the same ramer analysis by flow cytometry of DTH-derived T cells from patient 5. On the $y$-axis MHC class I tetramer PE staining and on the $x$-axis CD4 (e) or CD8 (f). Note the difference in fluorescence intensity in the tetramer positive population (MFI CD4:152 vs. MFI CD8:83) whereas the percentage of positive cells is equal $(17 \%)$. CD8+ cells visualized with the ABC-peroxidase kit with AEC (red-brown staining) as substrate in corresponding areas on tissue sections from tonsil fixed with acetone $(\mathbf{g})$ or PFA $(\mathbf{h})$

population of cells was co-stained with CD8 as compared to co-staining with CD4. While for staining of cells in suspension with MHC class I tetramer, samples were incubated at the same time with MHC class I tetramer and CD8, for the in situ protocol, samples were first stained with MHC class I tetramer followed by staining with CD8. This explains possible reduced staining intensity for $\mathrm{CD} 8$ in the in situ protocol, and reduced MHC class I tetramer staining intensity for the in vitro staining protocol. In addition, a direct comparison between CD8 staining efficiency in our $\mathrm{MHC}$ class I tetramer staining protocol and the more conventional CD8 staining method after acetone fixation revealed a major difference. As shown in Fig. 5 on tissue sections from tonsils, fewer and less intensely stained CD8+ cells are seen with the MHC class I tetramer staining protocol.

Although we can not exclude that a small part of the MHC class I tetramer-positive, CD8-negative cells result from non-specific binding of MHC class I tetramer to other non-CD8+ inflammatory cells, our findings indicate that: (a) MHC class I tetramer binding only occurred in accordance with the DTH challenge specificity, (b) MHC class I tetramer-positive cells were not found using the non-relevant MART-1, HIV and EBV tetramers, only with the tyrosinase and gp100 tetramers, (c) no tyrosinase or gp100-positive cells were found in DTH lesions derived from non-specific challenges (i.e., DC alone $[n=4]$ or DC loaded with $\mathrm{KLH}[n=3]$ ), (d) different staining patterns were obtained with the specific MHC class I tetramers and 
(e) the in situ results correlated with the in vitro results on $\mathrm{T}$ cell specificity clearly argue against a major involvement of non-specific binding. It is, however, important to include appropriate controls for the in situ detection of CTLs.

In earlier studies, in situ detection of antigen-specific $\mathrm{T}$ cells with $\mathrm{MHC}$ class I tetramers was performed on viable tissue sections of spleens of $\mathrm{T}$ cell receptor transgenic mice or spleens of mice adoptively transferred with specific $\mathrm{T}$ cells $[14,29,30]$. The application of this method was extended to human $\mathrm{T}$ cells in a skin explant assay for graft-versus-host CTL activity [12, 33]. A drawback of the method described in those studies is that it does not allow storage whereas storage of clinical material facilitates retrospective analyses. With the use of multimeric peptide/MHC class I complexes the need for viable material is circumvented, however, these tetramers are not readily available [2, 27, 31]. Therefore the method as we describe, although intricate, is very useful for the analyses of already frozen material from patients treated with peptide-based vaccines. Therefore we believe that this tetramer-based detection of antigen-specific $\mathrm{T}$ cells in frozen tissue sections may provide a valuable monitoring tool.

Acknowledgments We are grateful to F. A. Vyth-Dreese, K. Schepers H. Spits and T. Schumacher for providing precious material and for helpful suggestions. This study was supported by grants KUN 1995/1910, 1999/1950, 2000/2301, 2003/2893 and 2003/2917 from the Dutch Cancer Society and the TIL-foundation.

\section{References}

1. Altman JD, Moss PA, Goulder PJ, Barouch DH, McHeyzerWilliams MG, Bell JI, McMichael AJ, Davis MM (1996) Phenotypic analysis of antigen-specific T lymphocytes. Science 274:94-96

2. Andersen MH, Pedersen LO, Capeller B, Brocker EB, Becker JC, thor Straten P (2001) Spontaneous cytotoxic T-cell responses against survivin-derived MHC class I-restricted T-cell epitopes in situ as well as ex vivo in cancer patients. Cancer Res 61:59645968

3. Bakker AB, Schreurs MW, de Boer AJ, Kawakami Y, Rosenberg SA, Adema GJ, Figdor CG (1994) Melanocyte lineage-specific antigen gp100 is recognized by melanoma-derived tumor-infiltrating lymphocytes. J Exp Med 179:1005-1009

4. Balch CM, Cascinelli N (2001) The new melanoma staging system. Tumori 87:S64-S68

5. Banchereau J, Schuler-Thurner B, Palucka AK, Schuler G (2001) Dendritic cells as vectors for therapy. Cell 106:271-274

6. Boon T, Coulie PG, Van den Eynde BJ, van der Bruggen P (2006) Human $\mathrm{T}$ cell responses against melanoma. Annu Rev Immunol 24:175-208

7. Coulie PG, Karanikas V, Colau D, Lurquin C, Landry C, Marchand M, Dorval T, Brichard V, Boon T (2001) A monoclonal cytolytic T-lymphocyte response observed in a melanoma patient vaccinated with a tumor-specific antigenic peptide encoded by gene MAGE-3. Proc Natl Acad Sci USA 98:10290-10295
8. Coulie PG, van der Bruggen P (2003) T-cell responses of vaccinated cancer patients. Curr Opin Immunol 15:131-137

9. de Vries IJ, Bernsen MR, Lesterhuis WJ, Scharenborg NM, Strijk SP, Gerritsen MJ, Ruiter DJ, Figdor CG, Punt CJ, Adema GJ (2005) Immunomonitoring tumor-specific T cells in delayed-type hypersensitivity skin biopsies after dendritic cell vaccination correlates with clinical outcome. J Clin Oncol 23:5779-5787

10. de Vries IJ, Lesterhuis WJ, Scharenborg NM, Engelen LP, Ruiter DJ, Gerritsen MJ, Croockewit S, Britten CM, Torensma R, Adema GJ, Figdor CG, Punt CJ (2003) Maturation of dendritic cells is a prerequisite for inducing immune responses in advanced melanoma patients. Clin Cancer Res 9:5091-5100

11. Denkberg G, Cohen CJ, Reiter Y (2001) Critical role for CD8 in binding of MHC tetramers to TCR: CD8 antibodies block specific binding of human tumor-specific MHC-peptide tetramers to TCR. J Immunol 167:270-276

12. Dickinson AM, Wang XN, Sviland L, Vyth-Dreese FA, Jackson GH, Schumacher TN, Haanen JB, Mutis T, Goulmy E (2002) In situ dissection of the graft-versus-host activities of cytotoxic $\mathrm{T}$ cells specific for minor histocompatibility antigens. Nat Med $8: 410-414$

13. Figdor CG, de Vries IJ, Lesterhuis WJ, Melief CJ (2004) Dendritic cell immunotherapy: mapping the way. Nat Med 10:475-480

14. Haanen JB, van Oijen MG, Tirion F, Oomen LC, Kruisbeek AM, Vyth-Dreese FA, Schumacher TN (2000) In situ detection of virus- and tumor-specific T-cell immunity. Nat Med 6:1056-1060

15. Herr W, Wolfel T, Heike M, Meyer zum Buschenfelde KH, Knuth A (1994) Frequency analysis of tumor-reactive cytotoxic T lymphocytes in peripheral blood of a melanoma patient vaccinated with autologous tumor cells. Cancer Immunol Immunother 39:93-99

16. Hsu FJ, Benike C, Fagnoni F, Liles TM, Czerwinski D, Taidi B, Engleman EG, Levy R (1996) Vaccination of patients with B-cell lymphoma using autologous antigen-pulsed dendritic cells. Nat Med 2:52-58

17. Lesterhuis WJ, de Vries IJ, Schuurhuis DH, Boullart AC, Jacobs JF, de Boer AJ, Scharenborg NM, Brouwer HM, van de Rakt MW, Figdor CG, Ruers TJ, Adema GJ, Punt CJ (2006) Vaccination of colorectal cancer patients with CEA-loaded dendritic cells: antigen-specific T cell responses in DTH skin tests. Ann Oncol 17:974-980

18. Mukherji B, Chakraborty NG (1995) Immunobiology and immunotherapy of melanoma. Curr Opin Oncol 7:175-184

19. Nestle FO, Alijagic S, Gilliet M, Sun Y, Grabbe S, Dummer R, Burg G, Schadendorf D (1998) Vaccination of melanoma patients with peptide- or tumor lysate-pulsed dendritic cells. Nat Med 4:328-332

20. Parmiani G, Castelli C, Dalerba P, Mortarini R, Rivoltini L, Marincola FM, Anichini A (2002) Cancer immunotherapy with peptide-based vaccines: what have we achieved? Where are we going? J Natl Cancer Inst 94:805-818

21. Pichler WJ, Wolff-Vorbeck G, Birke C, Rieber P, Peter HH (1984) Comparison of the inhibitory activity of seven anti-T8 antibodies on specific cellular cytotoxicity. Immunobiology 167:376-388

22. Pittet MJ, Speiser DE, Valmori D, Rimoldi D, Lienard D, Lejeune F, Cerottini JC, Romero P (2001) Ex vivo analysis of tumor antigen specific CD8+ T cell responses using MHC/peptide tetramers in cancer patients. Int Immunopharmacol 1:1235-1247

23. Romero P, Cerottini JC, Waanders GA (1998) Novel methods to monitor antigen-specific cytotoxic $\mathrm{T}$-cell responses in cancer immunotherapy. Mol Med Today 4:305-312

24. Romero P, Dunbar PR, Valmori D, Pittet M, Ogg GS, Rimoldi D, Chen JL, Lienard D, Cerottini JC, Cerundolo V (1998) Ex vivo staining of metastatic lymph nodes by class I major histocompatibility complex tetramers reveals high numbers of antigen-experienced tumor-specific cytolytic $\mathrm{T}$ lymphocytes. J Exp Med 188:1641-1650 
25. Romero P, Pannetier C, Herman J, Jongeneel CV, Cerottini JC, Coulie PG (1995) Multiple specificities in the repertoire of a melanoma patient's cytolytic $\mathrm{T}$ lymphocytes directed against tumor antigen MAGE-1A.1. J Exp Med 182:1019-1028

26. Romero P, Pittet MJ, Valmori D, Speiser DE, Cerundolo V, Lienard D, Lejeune F, Cerottini JC (2000) Immune monitoring in cancer immunotherapy. Ernst Schering Res Found Workshop 30:75-97

27. Schrama D, Pedersen LO, Keikavoussi P, Andersen MH, Straten Pt P, Brocker EB, Kampgen E, Becker JC (2002) Aggregation of antigen-specific $\mathrm{T}$ cells at the inoculation site of mature dendritic cells. J Invest Dermatol 119:1443-1448

28. Schreurs MW, Eggert AA, de Boer AJ, Vissers JL, van Hall T, Offringa R, Figdor CG, Adema GJ (2000) Dendritic cells break tolerance and induce protective immunity against a melanocyte differentiation antigen in an autologous melanoma model. Cancer Res 60:6995-7001

29. Skinner PJ, Daniels MA, Schmidt CS, Jameson SC, Haase AT (2000) Cutting edge: In situ tetramer staining of antigen-specific T cells in tissues. J Immunol 165:613-617
30. Skinner PJ, Haase AT (2002) In situ tetramer staining. J Immunol Methods 268:29-34

31. Straten P, Dahl C, Schrama D, Pedersen LO, Andersen MH, Seremet T, Brocker EB, Guldberg P, Becker JC (2006) Identification of identical TCRs in primary melanoma lesions and tumor free corresponding sentinel lymph nodes. Cancer Immunol Immunother 55:495-502

32. Thurner B, Haendle I, Roder C, Dieckmann D, Keikavoussi P, Jonuleit H, Bender A, Maczek C, Schreiner D, von den Driesch P, Brocker EB, Steinman RM, Enk A, Kampgen E, Schuler G (1999) Vaccination with mage-3A1 peptide-pulsed mature, monocyte-derived dendritic cells expands specific cytotoxic T cells and induces regression of some metastases in advanced stage IV melanoma. J Exp Med 190:1669-1678

33. Vyth-Dreese FA, Kim YH, Dellemijn TA, Schrama E, Haanen JB, Spierings E, Goulmy E (2006) In situ visualization of antigen-specific $\mathrm{T}$ cells in cryopreserved human tissues. J Immunol Methods 310:78-85

34. Xu XN, Screaton GR (2002) MHC/peptide tetramer-based studies of $\mathrm{T}$ cell function. J Immunol Methods 268:21-28 